\title{
Health and Well-Being in Midlife Parents of Children With Special Health Needs
}

\author{
Amy M. Smith, MS and Joseph G. Grzywacz, PhD \\ Oklahoma State University
}

\begin{abstract}
The objectives of this study were to delineate variation in mental and physical health outcomes over a 10-year period among parents with a child with special health needs as compared to parents of a typically developing child; and evaluate the possible protective effects of parental perceived control and social support. The sample consisted of 646 parents from the longitudinal Midlife Development in the United States (MIDUS) study. Nearly one-quarter of the sample $(n=128 ; 22.3 \%)$ reported having a child with a special health care need. Cross-sectional analyses indicated that parents of a child with special care needs reported poorer self-rated mental health, greater depressive symptoms, and more restrictions in instrumental activities of daily living (IADL). Parents of a child with special health care needs had greater increases in depressive symptoms over time and greater declines in instrumental activities of daily living than parents of typically developing children. Perceived control was a robust predictor of all health outcomes over time. The added stressors of parenting a child with special health needs may undermine the long-term health of parents. Behavioral interventions and clinical practices that facilitate parental perceived control may enable resilience and better health.
\end{abstract}

Keywords: parental health, depressive symptoms, well-being, children with special health needs, disabilities

Parenting a child with a special health need can pose stressors beyond those experienced raising typically developing children (Baxter, Cummins, \& Yiolitis, 2000; Butcher, Wind, \& Bouma, 2008; DeLambo, Chung, \& Huang, 2011; Dellve, Samuelsson, Tallborn \& Fasth, 2006; Gerstein, Crnic, Blacher, \& Baker, 2009; Glenn, Cunningham, Poole, Reeves, \& Weindling, 2009; Herring et al., 2006). Caring for a child with a special health need may increase stress levels because of elevated medical expenses, time demands, physical care, and worry about the child's future (Brehaut et al., 2011;

This article was published Online First April 21, 2014.

Amy M. Smith, MS, and Joseph G. Grzywacz, PhD, Department of Human Development and Family Science, Oklahoma State University.

This research was supported by a grant from the National Institutes on Aging (2P01AG020166-07).

Correspondence concerning this article should be addressed to Amy M. Smith, MS, c/o Joseph G. Grzywacz, $\mathrm{PhD}$, Oklahoma State University, 700 North Greenwood Avenue, Tulsa, OK 74106. E-mail: amy.michelle.smith@ okstate.edu
Weiss, 2002). Further, evidence suggests that increased exposure to stressors can pose serious health threats and potentially increase the risk of poor health outcomes for parents (Hung, Wu, Chiang, Wu, \& Yeh, 2010; Thurston et al., 2011; Witt, Gottlieb, Hampton, \& Litzelman, 2009).

Researchers have studied the mental health, especially depressive symptoms, of parents with a child with special health needs. Researchers have posited that the elevated exposure to stressors that may accompany parenting a child with special health needs lead to elevated rates of depressive symptoms and depression in parents (Bailey, Golden, Roberts, \& Ford, 2007; Dellve et al., 2006; Hastings, 2003; Lovell, Moss, \& Wetherell, 2012). Several studies found that diagnosed depression and depressive symptoms were higher for mothers (Eisenhower, Baker, \& Blacher, 2009; Brehaut et al., 2009; Glidden \& Schoolcraft, 2003; Olsson \& Hwang, 2001; Resch, Elliot, \& Benz, 2012; Sawyer et al., 2010) and fathers (Ha, Hong, Seltzer, \& Greenberg, 2008; Hastings, 2003) with a child with special health needs. Sawyer et al. (2010) found 
significantly higher rates of depression for mothers of children with autism than for mothers of typically developing children. Glidden and Schoolcraft (2003) also found initial high levels of depressive symptoms for birth parents of children with an intellectual disability; however, symptomatology attenuated over time suggesting the mental health implications of parenting a special health needs child may be temporary and subject to adaptation.

Substantial cross-sectional evidence suggests parenting a child with special health needs may undermine parents' physical health outcomes (Allik, Larson, \& Smedje, 2006; Brehaut et al., 2004; Brehaut et al., 2009; Burton, Lethbridge, \& Phipps, 2008; Eisenhower et al., 2009; Feldman et al., 2007). Witt et al., (2009) reported the prevalence of activity limitations as being twice as high among parents of children with disabilities $(23.1 \%$ vs. $11.9 \%)$. Other cross-sectional studies found higher levels of physical problems, including back pain and functional limitations, for mothers of children with cerebral palsy than mothers of typically developing children (Brehaut et al., 2004; Kaya et al., 2010; Tong et al., 2002; Tong et al., 2003). One longitudinal study based on a clinical sample reported that parents of a young child with developmental delays had poorer self-rated general health than parents of comparably aged typically developing children (Eisenhower et al., 2009). Additional longitudinal, population based studies are needed to determine long-term physical health implications of parenting a child who has a special health care need.

Resilience theories suggest that perceived control and social support promote successful adaptation by individuals exposed to challenging circumstances (Walsh, 2012; Wright, Masten, \& Narayan, 2013). Parents raising a child with a special health need often report insufficient supports and feelings of helplessness (Butcher et al., 2008; Florian \& Findler, 2001). Parents of special health needs children can lose a sense of control as the health care system assumes greater responsibility for the child's well-being (Bailey et al., 2007). A sense of control is important for minimizing stress experienced by parents of children with special needs (Butcher et al., 2008) and for protecting mental health outcomes (Weiss, 2002). Similarly, several cross-sectional studies using convenience samples report that social support is associated with better health outcomes for parents with a child with special health needs (Horton \& Wallander, 2001; Gerstein et al., 2009; Keller \& Honig, 2004; Sarason, Sarason, \& Pierce, 1990; Thurston et al., 2011). Additional research demonstrates that social support lessens the experience of stress in parents with a child with disabilities (Boyce, Behl, Mortensen, \& Akers, 1991; Bristol, 1984; Weiss, 2002). Missing from the literature regarding families of children with special health care needs is evidence of the protective effects of perceived control and social support over long periods of time.

Guided by the risk and resilience framework, we study the long-term health implications of raising a child with special health needs. We propose that parenting a child with special health needs can be a risk factor for poor health outcomes, whereas social support and parental sense of control may promote resilience by exerting protective health effects for parents' health and well-being. This study has two primary aims: (a) delineate variation between parents with a child with special health needs as compared with parents of a typically developing child in mental and physical health outcomes over a 10-year period; and (b) determine whether selected resilience factors-parental perceived control and support-influence these trajectories of parental health outcomes.

\section{Method}

\section{Sample}

The data for this study are from the Midlife Development in the United States (MIDUS) survey. MIDUS was originally fielded in 1995 to 1996 to a nationally representative sample of 25- to 74-year-old, English-speaking adults. The response rate for the MIDUS baseline data collection was $60.8 \%$. MIDUS respondents were recontacted in 2004 (MIDUS 2). The longitudinal retention rate of the original random digit dial subsample with complete data was $69 \%(n=3140)$. The analytic sample for this analysis $(n=646)$ consists of individuals from the original random digit dial subsample who had one or more children under age 18 at baseline, and who completed all MIDUS and MIDUS 2 survey data collection (see Table 1, for parent demographics). 
Table 1

Baseline Description of Parents in the Analytic Sample

\begin{tabular}{|c|c|c|c|c|c|c|c|}
\hline \multirow[b]{2}{*}{ Variable } & \multirow[b]{2}{*}{$\%$} & \multicolumn{2}{|c|}{ Mean } & \multicolumn{2}{|r|}{$S D$} & \multicolumn{2}{|c|}{ Range } \\
\hline & & Age & Income & Age & Income & Age & Income \\
\hline Age & & 39 years & $\$ 55,620$ & 7.69 & $\$ 45597.31$ & $25-66$ years & $\$ 0$ to $\$ 300,000$ \\
\hline Female & 53.56 & & & & & & \\
\hline Male & 46.44 & & & & & & \\
\hline Non-Hispanic White & 87.8 & & & & & & \\
\hline Ethnic or racial minority & 12.2 & & & & & & \\
\hline Currently married & 78.5 & & & & & & \\
\hline Never married & 3.5 & & & & & & \\
\hline Divorced & 13.9 & & & & & & \\
\hline Widowed & 0.8 & & & & & & \\
\hline
\end{tabular}

\section{Measures}

Child with special health need. Participants were asked to indicate (yes $=1$, no $=0$ ) whether their child had a "chronic disease or disability" or "emotional problems" (yes $=1$, no $=0$ ) within the past 12 months. Parents were classified as having a child with a special health need if they responded "yes" to either question. Participants who responded "no" to both questions were classified as not having a child with a special health condition (i.e., typically developing children).

Parental physical health. Self-rated physical health was measured by asking parents to rate their physical health on a 5-point scale, ranging from 1 (poor) to 5 (excellent). Limitations in instrumental activities of daily living (7 items) assessed the degree to which an individual's health limited important daily activities (e.g., lifting or carrying groceries, climbing several flights of stairs, walking more than a mile). Response options ranged from 1 (a lot) to 4 (not at all). Responses were reverse scored and averaged such that higher scores reflected greater limitations in activities of daily living.

Parental mental health. Depressive symptoms were measured with the Composite International Diagnostic Interview Short Form, which is based on the Diagnostic and Statistical Manual of Mental Disorders, third edition, revised (DSM-III-R; Wang, Berglund, \& Kessler, 2000). Self-rated mental health asked parents to rate their mental and emotional health on a 5-point scale, ranging from 1 (poor) to 5 (excellent).

Parental social support. Three measures of social support were used. Receive instrumen- tal support from family/friends was assessed with four items asking how many hours per month the respondent received unpaid assistance (i.e., childcare, help around the house) from family and friends. Receive instrumental support from other sources was assessed with four items asking participants to report the number of hours of unpaid assistance (i.e., childcare, transportation) obtained each month from other sources including government and church. Both instrumental support variables were determined by calculating the mean hours of support received, but were subsequently dichotomized (yes $=1$, no $=0$ ) because of heavy right skew. Receive emotional support was assessed with six items asking the number of hours per month the respondent received emotional support (i.e., getting advice, or having someone listen to you) from family and friends (Grzywacz \& Marks, 1999; Rossi, 2001; Rossi, 2004). This variable was created by calculating the mean hours received from each support source (i.e., spouse, children, parent, or in-law). Emotional support was then recoded into a dichotomous variable of high emotional support (yes $=1$, no $=0$ ) with high emotional support being greater than 11 hours a month because of heavy left skew in reported hours emotional support was received.

Parental perceived control. Perceived control was assessed with 12 items measuring the extent to which an individual believed that she/he determined her/his circumstances and outcomes. Statements included those reflecting perceived mastery (e.g., I can do just about anything I really set my mind to) as well as perceived constraints (e.g., There is really no way I can solve the problems I have). Response 
options for the subscales ranged from 1 (strongly agree) to 7 (strongly disagree). Appropriate items were reverse scored and then averaged so that higher values indicated greater perceived control (Cronbach's alpha $=.85$; Lachman \& Weaver, 1998).

\section{Analytic Sequence}

Descriptive statistics and bivariate correlations were calculated to describe the sample, to determine the distributions of analytic variables, and to explore simple correlations. Ordinary least squares regression models were fit to examine differences in health outcomes among parents of children with special needs and those with typically developing children, and to study the independent associations of perceived control and social support with health. Regression models for each health outcome were fit with both cross-sectional and longitudinal data, and each model controlled for the effects of age, education level, marital status, and ethnicity. Cross-lagged regression models were fit to determine whether long-term health outcomes differed based on whether an individual had a child with a special health care need. Gender differences were explored by adding multiplicative interaction terms to each regression equation.

\section{Results}

Nearly one-quarter of the sample $(n=128$; $22.3 \%$ ) reported having a child with special health needs, whereas the remainder $(n=445$, $77.7 \%$ ) reported that none of their children had either a "chronic disease or disability" or "an emotional problem."

\section{Mental Health}

Results from the cross-sectional original MIDUS data indicated that parents with a child with special health needs have significantly lower ratings of overall self-rated mental health and significantly higher levels of depressive symptoms as compared to parents without a child with special health needs (see Table 2). Higher levels of control were associated with better self-rated mental health and fewer depressive symptoms. Control was negatively related to depressive symptoms. Differences in the association between control and depressive symp-

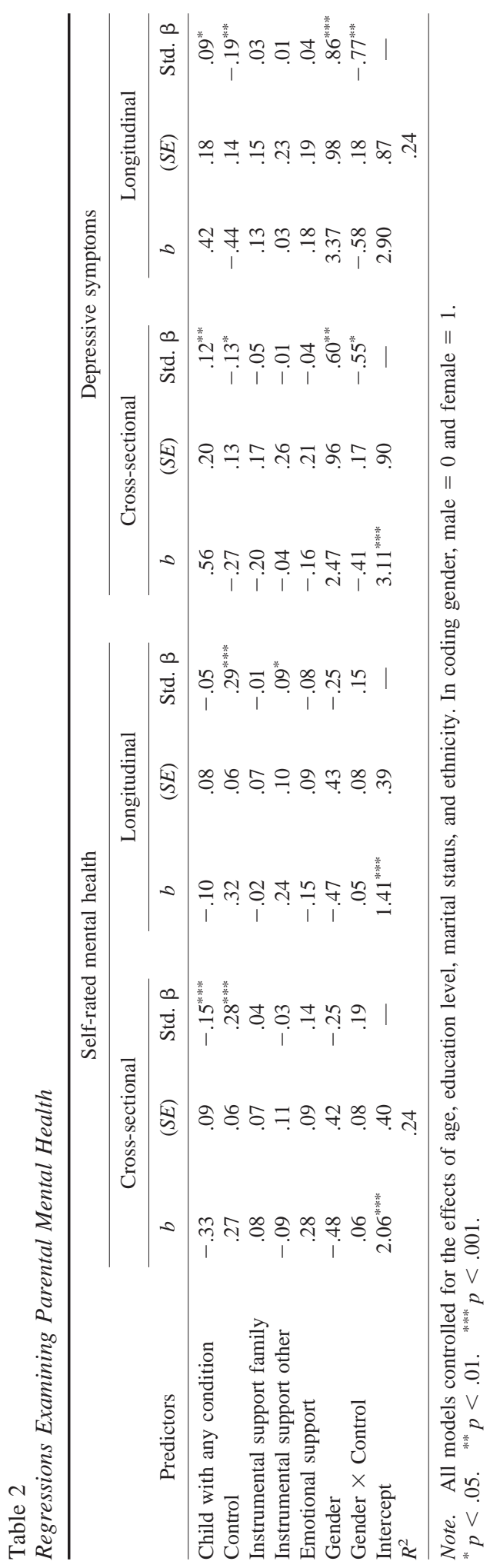


toms were more pronounced for women than men, such that control was more strongly related to depressive symptoms for women versus men. There was no evidence that social support was associated with either mental health outcome in cross-sectional analyses.

Results from cross-lagged regression models using longitudinal data indicated no long-term differences in self-rated mental health between parents with and without a child with special health needs. However, parents with a child with special health needs at Time I predicted higher depressive symptoms 10 years later (see Table 2). Greater control at baseline predicted better self-rated mental health over time and fewer rated depressive symptoms. The gender interaction found for control in the prediction of depressive symptoms in the cross-sectional analysis persisted over time. Specifically, control had a stronger, negative relationship to depressive symptoms for women than men. A high level of instrumental support from outside the family at Time 1 predicted better self-rated mental health across the 10-year period; otherwise, there was no evidence that social support affected either mental health outcome over time.

\section{Physical Health}

There was no evidence of differences in selfrated physical health among parents with and without a child with special health needs (see Table 3). However, a second operational form of parental physical health-limitations in instrumental activities of daily living-was elevated among parents with a child with special health needs in both cross sectional and longitudinal analyses. In considering the resilience factors, control was significantly and negatively related to self-rated physical health and limitations in instrumental activities of daily living. Social support was not related to either physical health outcome. No gender interactions existed for parenting a child with special health needs or control and physical health outcomes.

\section{Discussion}

This analysis used a U.S.-based, populationbased sample of parents to examine how parenting a child with special health needs may affect the health and wellbeing of adults over a

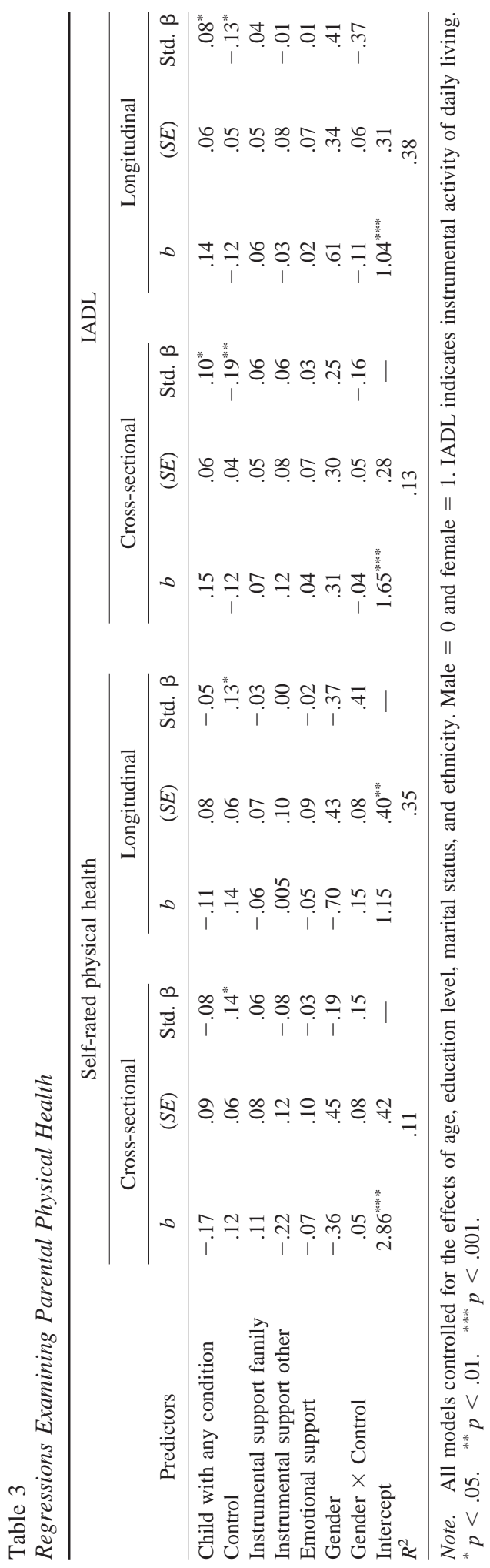


10-year period. Additionally, parents' sense of control and social support were studied as potential protective factors. Results offer further evidence that children's special health needs may undermine parents' physical and mental health. Like previous research, (Brehaut et al., 2009; Feldman et al., 2007; Resch et al., 2012), our cross-sectional results found significant differences in physical (limitations in activities of daily living) and mental health (e.g., self-rated mental health and depressive symptoms). Our results extend this previous research by finding physical and mental health consequences in a more general definition of child health problem in a U.S. population-based sample.

Newer to the literature is our results suggesting that parenting a child with special health needs may have long-term health consequences for adults. Indeed, we found that being a parent with a child with special health needs was associated with greater restrictions in activities of daily living and greater depressive symptoms 10 years later. Importantly, these results held controlling for earlier observations of these health outcomes suggesting that parents of children with special health care needs have greater health declines than parents of typically developing children. Although previous longitudinal research reported greater health declines over time for parents with a child with special health needs (Brehaut et al., 2011; Burton et al., 2008; Eisenhower, Baker, \& Blacher, 2009; Herring et al., 2006), most of this research used comparatively short-term follow-up periods, such as 1 to 2 years (Eisenhower et al., 2009; Herring et al., 2006). Our results indicating greater physical disability and depressive symptoms across a 10 -year period offer reason for practical concern and policy attention. That is, in light of evidence indicating that the proportion of children with a special health care need has grown, our results suggest that the increasing number of parents caring for these children (National Survey of Children with Special Health Care Needs, 2009/2010) will experience steeper health declines because of their child's condition.

Despite these notable health declines, it is also noteworthy that one cross-sectional difference in health was attenuated to nonsignificance over time. Specifically, Time 1 measurements illustrated that self-rated mental health was significantly and negatively related to parenting a child with a special health care need. Time 2 measurements (10 years later) no longer showed a significant relationship between parenting a child with special health care need and selfrated mental health of parents. This finding is in contrast to one study that found parents' selfrated general health incrementally worsened over 10 years (Brehaut et al., 2011). The attenuation of differences in self-rated health over time suggests evidence of resilience in parents (Brehaut et al., 2011). The current findings are consistent with a resilience framework in that parents of children with special health care needs, through protective processes or other resources, are able to thrive despite challenges often associated with parenting a child with special health care needs. As time goes by, parents of children with special health care needs likely learn new skills and attitudes that can help them adjust to their children's conditions (Luthar, Cicchetti, \& Becker, 2000).

We found no evidence that the health effects of parenting a child with a special health care need differed for mothers and fathers. This finding is contrary to some previous research (Allik et al., 2006; Eisenhower, Baker, \& Blacher, 2009), but is also supported by other research (Hastings, 2003), including one previous study based on cross-sectional MIDUS 2 data (Ha et al., 2008). In previous research, parenting a child with a special health care need has been hypothesized to affect the health of mothers more strongly than fathers because mothers are presumed to take on a greater caregiving burden than fathers (Ross \& Van Willigen, 1996). Our findings, along with previous literature (Ha et al., 2008), suggest that it is important to include surveys from both the mothers' and fathers' perspectives to accurately determine the influence of child health conditions on parental health.

Although no gender differences were found in health consequences of parenting a child with a special health care need, consistent gender differences in the effects of control on health outcomes were observed. Our results suggest that the main gender differences for control exist solely for depressive symptoms, and that perceived control is more protective for women than men. This result may suggest that women's greater interactions with the health care system may make them more vulnerable to feelings of helplessness and subsequent depressive symp- 
toms. This is an important area for future research. Gender differences notwithstanding, control was a consistent protective factor across all the health outcomes and they persisted over time. These results are consistent with previous quantitative (Duchovic, Gerkensmeyer, \& Wu, 2009) and qualitative studies (Knox, Parmenter, Atkinson, \& Yazbeck, 2000). Our findings extend this literature by demonstrating the longterm salience of perceived control in protecting the health of parents who have children with special health care needs.

The absence of meaningful protective effects for social support is also noteworthy. Results yielded little evidence that social support (i.e., instrumental support from family, instrumental support from others, and emotional support) protected adult health. Contrary to some previous research and our hypotheses, social support was not significantly related to either physical or mental health outcomes (Feldman et al., 2007; Guralnick, Hammond, Neville, \& Connor, 2008; Shin, Nhan, Crittenden, Flory, \& Ladinsky, 2006). However, our measures of support assessed the hours of total support received and did not assess for any functional measures of support such as number of support sources, satisfaction with support, or content of support (Resch et al., 2012).

The study's limitations must be considered while interpreting the results. The absence of a direct assessment of parenting stress did not allow a direct evaluation of the hypothesis that the psychological wear and tear of parenting a child with special health care needs contributes to generally poorer health outcomes. The relatively coarse assessment of whether participants had a child with a special health condition is another limitation that likely underestimates the long-term health implications of parenting a child with special needs. We could also not determine whether participants had more than one child with a special health care need. The social support measures were also comparatively weak because they only captured hours of support received without considering whether provided support was consistent with the need, or useful to the individual receiving the support. Although measurement challenges like these are not uncommon in broad national surveys, the limitation highlights the need for additional longitudinal research with more refined measures. Limitations notwithstanding, our findings add to the previous literature and can be informative for clinicians and educators working with families with children with special health care needs.

The results of this study suggest health care and service providers need to consider the health of parents caring for children with health conditions. Elevated depressive symptoms and greater limitations in activities of daily living among parents of children with special health needs is concerning in itself, but they potentially double the impact if these health declines compromise their ability to care for their child with special health care needs. Our findings support the importance of interventions targeting both mothers and fathers of children with special health care needs. Interventions could emphasize motivational interviewing techniques to maintain or build a sense of control. Finally, our results highlight the reality that policies supporting families of children with special health care needs should not be diagnosis - or disorderspecific.

In summary, parenting a child with special health care needs is associated with elevated depressive symptoms and greater restrictions in activities of daily living over time for both mothers and fathers. Perceived control was protective against most negative health outcomes. These findings extend previous research by documenting long-term health declines associated with parenting a child with special health care needs, using a more generalizable sample. Although more research is needed, the results suggest the need for programmatic and policy solutions to support and protect parents of children with special health care needs.

\section{References}

Allik, H., Larson, J. O., \& Smedje, H. (2006). Healthrelated quality of life in parents of school-age children with Asperger syndrome or highfunctioning autism. Health and Quality of Life Outcomes, 4, 1-8. doi:10.1186/1477-7525-4-1

Bailey, D. B., Golden, R. N., Roberts, J., \& Ford, A. (2007). Maternal depression and developmental disability: Research critique. Mental Retardation and Developmental Disabilities Research Reviews, 13, 321-329. doi:10.1002/mrdd.20172 
Baxter, C., Cummins, R. A., \& Yiolitis, L. (2000). Parental stress attributed to family members with and without disability: A longitudinal study. Journal of Intellectual and Developmental Disability, 25, 105-118. doi:10.1080/13269780050033526

Boyce, G., Behl, D., Mortensen, L., \& Akers, J. (1991). Child characteristics, demographics, and family processes: Their effects on families of children with disabilities. Counseling Psychology Quarterly, 4, 273-288. doi:10.1080/09515079108254436

Brehaut, J. C., Garner, R. E., Miller, A. R., Lach, L. M., Klassen, A. F., Rosenbaum, P. L., \& Kohen, D. E. (2011). Changes over time in the health of caregivers of children with health problems: Growth-curve findings from a 10-year Canadian population-based study. American Journal of Public Health, 101, 2308-2316. doi:10.2105/AJPH .2011 .300298

Brehaut, J. C., Kohen, D. E., Garner, R. E., Miller, A. R., Lach, L. M., Klassen, A. F., \& Rosenbaum, P. L. (2009). Health among caregivers of children with health problems: Findings from a Canadian population-based study. American Journal of Public Health, 99, 1254-1262. doi:10.2105/AJPH .2007 .129817

Brehaut, J. C., Kohen, D. E., Parminder, R., Walter, S. D., Russell, D. J., Swinton, M., . . Rosenbaum, P. (2004). The health of primary caregivers of children with Cerebral Palsy: How does it compare with that of other Canadian caregivers? Pediatrics, 114, 182-191. doi:10.1542/peds.114.2.e182

Bristol, M. M. (1984). Family resources and successful adaptation to autistic children. In E. Schopler \& G. B. Mesibov (Eds.), The effects of autism on the family (pp. 289-310). New York, NY: Plenum Press. doi:10.1007/978-1-4899-2293-9_17

Burton, P., Lethbridge, L., \& Phipps, S. (2008). Children with disabilities and chronic conditions and longer-term parental health. The Journal of SocioEconomics, 37, 1168-1186. doi:10.1016/j.socec .2007 .01 .032

Butcher, P. R., Wind, T., \& Bouma, A. (2008). Parenting stress in mothers and fathers of a child with a hemiparesis: Sources of stress, intervening factors and long-term expressions of stress. Child: Care, Health and Development, 34, 530-541. doi: 10.1111/j.1365-2214.2008.00842.x

DeLambo, D., Chung, W., \& Huang, W. (2011). Stress and age: A comparison of Asian American and Non-Asian American parents of children with developmental disabilities. Journal of Developmental and Physical Disabilities, 23, 129-141. doi:10.1007/s10882-010-9211-3

Dellve, L., Samuelsson, L., Tallborn, A., \& Fasth, A. (2006). Stress and well-being among parents of children with rare diseases: A prospective intervention study. Journal of Advanced Nursing, 53, 392-402. doi:10.1111/j.1365-2648.2006.03736.x
Duchovic, C. A., Gerkensmeyer, J. E., \& Wu, J. (2009). Factors associated with parental distress. Journal of Child and Adolescent Psychiatric Nursing, 22, 40-48. doi:10.1111/j.1744-6171.2008 .00168 .

Eisenhower, A. S., Baker, B. L., \& Blacher, J. (2009). Children's delayed development and behavior problems: Impact on mothers' perceived physical health across early childhood. Social Science \& Medicine, 68, 89-99. doi:10.1016/j.socscimed .2008 .09 .033

Feldman, M., McDonald, L., Serbin, L., Stack, D., Secco, M. L., \& Yu, C. T. (2007). Predictors of depressive symptoms in primary caregivers of young children with or at risk for developmental delay. Journal of Intellectual Disability Research, 51, 606-619. doi:10.1111/j.1365-2788.2006 .00941.x

Florian, V., \& Findler, L. (2001). Mental health and marital adaptation among mothers of children with cerebral palsy. American Journal of Orthopsychiatry, 71, 358-367. doi:10.1037/0002-9432.71.3 .358

Gerstein, E. D., Crnic, K. A., Blacher, J., \& Baker, B. L. (2009). Resilience and the course of daily parenting stress in families of young children with intellectual disabilities. Journal of Intellectual Disability Research, 53, 981-997. doi:10.1111/j .1365-2788.2009.01220.x

Glenn, S., Cunningham, C., Poole, H., Reeves, D., \& Weindling, M. (2009). Maternal parenting stress and its correlates in families with a young child with cerebral palsy. Child: Care, Health and Development, 35, 71-78. doi:10.1111/j.1365-2214 .2008.00891.x

Glidden, L. M., \& Schoolcraft, S. A. (2003). Depression: Its trajectory and correlates in mothers rearing children with intellectual disability. Journal of Intellectual Disability Research, 47, 250-263. doi: 10.1046/j.1365-2788.2003.00487.x

Grzywacz, J. G., \& Marks, N. F. (1999). Family solidarity and health behaviors: Evidence from the National Survey of Midlife Development in the United States. Journal of Family Issues, 20, 243268. doi:10.1177/019251399020002004

Guralnick, M. J., Hammond, M. A., Neville, B., \& Connor, R. T. (2008). The relationship between sources and functions of social support and dimensions of child- and parent-related stress. Journal of Intellectual Disability Research, 52, 1138-1154. doi:10.1111/j.1365-2788.2008.01073.x

Ha, J. H., Hong, J., Seltzer, M. M., \& Greenberg, J. S. (2008). Age and gender differences in the wellbeing of midlife and aging parents with children with mental health or developmental problems: Report of a national study. Journal of Health and Social Behavior, 49, 301-316. doi:10.1177/ 002214650804900305 
Hastings, R. P. (2003). Child behavior problems and partner mental health as correlates of stress in mothers and fathers of children with autism. Journal of Intellectual Disability Research, 47, 231237. doi:10.1046/j.1365-2788.2003.00485.x

Herring, S., Gray, K., Taffe, J., Tong, B., Sweeney, D., \& Einfield, S. (2006). Behavior and emotional problems in toddlers with pervasive developmental disorders and developmental delay: Associations with parental mental health and family functioning. Journal of Intellectual Disability Research, 50, 874-882. doi:10.1111/j.1365-2788.2006 $.00904 . \mathrm{x}$

Horton, T. V., \& Wallander, J. L. (2001). Hope and social support as resilience factors against psychological distress of mothers who care for children with chronic physical conditions. Rehabilitation Psychology, 46, 382-399. doi:10.1037/0090-5550 .46 .4 .382

Hung, J., Wu, Y., Chiang, Y., Wu, W., \& Yeh, C. (2010). Mental health of parents having children with physical disabilities. Chang Gung Medical Journal, 33, 82-91.

Kaya, K., Unsal-Delilioglu, S., Ordu-Gokkaya, N. K., Ozisler, Z., Ergun, N., Ozel, S., \& Ucan, H. (2010). Musculo-skeletal pain, quality of life and depression in mothers of children with cerebral palsy. Disability and Rehabilitation, 32, 16661672. doi:10.3109/09638281003649912

Keller, D., \& Honig, A. S. (2004). Maternal and paternal stress in families with school-aged children with disabilities. American Journal of Orthopsychiatry, 74, 337-348. doi:10.1037/0002-9432 .74.3.337

Knox, M., Parmenter, T. R., Atkinson, N., \& Yazbeck, M. (2000). Family control: The views of families who have a child with an intellectual disability. Journal of Applied Research in Intellectual Disabilities, 13, 17-28.

Lachman, M. E., \& Weaver, S. L. (1998). The sense of control as a moderator of social class differences in health and well-being. Journal of Personality and Social Psychology, 74, 763-773. doi:10.1037/00223514.74.3.763

Lovell, B., Moss, M., \& Wetherell, M. A. (2012). With a little help from my friends: Psychological, endocrine and health corollaries of social support in parental caregivers of children with autism or ADHD. Research in Developmental Disabilities, 33, 682-687. doi:10.1016/j.ridd.2011.11.014

Luthar, S. S., Cicchetti, D., \& Becker, B. (2000). The construct of resilience: A critical evaluation and guidelines for future work. Child Development, 71, 543-562. doi:10.1111/1467-8624.00164

National Survey of Children with Special Health Care Needs (NS-CSHCN). (2009/2010). Data query from the Child and Adolescent Health Measurement Initiative, Data Resource Center for
Child and Adolescent Health Web site. Retrieved October 17, 2012, from www.childhealthdata.org

Olsson, M. B., \& Hwang, C. P. (2001). Depression in mothers and fathers of children with intellectual disability. Journal of Intellectual Disability Research, 45, 535-543. doi:10.1046/j.1365-2788 .2001.00372.x

Resch, J. A., Elliot, T. R., \& Benz, M. R. (2012). Depression among parents of children with disabilities. Families, Systems, \& Health, 30, 291-301. doi: $10.1037 / \mathrm{a} 0030366$

Ross, C. E., \& Van Willigen, M. (1996). Gender, parenthood, \& anger. Journal of Marriage and the Family, 58, 572-584. doi:10.2307/353718

Rossi, A. S. (2001). Domains and dimensions of social responsibility: A sociodemographic profile. In A. S. Rossi (Ed.), Caring and doing for others: Social responsibility in the domains of family, work, and community (pp. 97-134). Chicago, IL: University of Chicago Press.

Rossi, A. S. (2004). Social responsibility to family and community. In O. G. Brim, C. D. Ryff, \& R. C. Kessler (Eds.), How healthy are we? A national study of well-being at midlife (pp. 550-585). Chicago, IL: University of Chicago Press.

Sarason, B. R., Sarason, I. G., \& Pierce, G. R. (1990). Traditional views of social support and their impact on assessment. In B. R. Sarason, I. G. Sarason, \& G. R. Pierce (Eds.), Social support: An interactional view (pp. 9-25). New York, NY: Wiley.

Sawyer, M. J., Bittman, M. L. A., Greca, A. M., Crettenden, A. D., Harchak, T. F., \& Martin, J. (2010). Time demands of caring for children with autism: What are the implications for maternal mental health? Journal of Autism and Developmental Disorders, 40, 620-628. doi:10.1007/ s10803-009-0912-3

Shin, J., Nhan, N. V., Crittenden, K. S., Flory, M., \& Ladinsky, J. (2006). Parenting stress of mothers and fathers of young children with cognitive delays in Vietnam. Journal of Intellectual Disability Research, 50, 748-760. doi:10.1111/j.1365-2788 .2006.00840.x

Thurston, S., Paul, L., Loney, P., Ye, C., Wong, M., \& Browne, G. (2011). Associations and costs of parental symptoms of psychiatric distress in a multi-diagnosis group of children with special needs. Journal of Intellectual Disability Research, 55, 263-280. doi:10.1111/j.1365-2788.2010 $.01356 . x$

Tong, H. C., Haig, A. J., Nelson, V. J., Yamakawa, K. J., Kandala, G., \& Shin, K. Y. (2003). Low back pain in adult female caregivers of children with physical disabilities. Archives of Pediatrics and Adolescent Medicine, 157, 1128-1133. doi:10.1001/ archpedi.157.11.1128 
Tong, H. C., Kandala, G., Haig, A. J., Nelson, V. S., Yamakawa, K. J., \& Shin, K. Y. (2002). Physical functioning in female caregivers of children with physical disabilities compared with female caregivers of children with a chronic medical condition. Archives of Pediatrics and Adolescent Medicine, 156, 1138-1142. doi:10.1001/archpedi.156 .11 .1138

Walsh, F. (2012). Family resilience: Strengths forged through adversity. In F. Walsh (Ed.), Normal family processes: Growing diversity and complexity (4th ed., pp. 399-427). New York: NY: Guilford Press.

Wang, P. S., Berglund, P., \& Kessler, R. C. (2000). Recent care of common mental disorder in the United States: Prevalence and conformance with evidence-based recommendations. Journal of General Internal Medicine, 15, 284-292. doi:10.1046/ j.1525-1497.2000.9908044.x

Weiss, M. J. (2002). Hardiness and social support as predictors of stress in mothers of typical children, children with autism, and children with mental retardation. Autism, 6, 115-130. doi:10.1177/ 1362361302006001009

Witt, W. P., Gottlieb, C. A., Hampton, J., \& Litzelman, K. (2009). The impact of childhood activity limitations on parental health, mental health, and workdays lost in the United States. Academic Pediatrics, 9, 263-269. doi:10.1016/j.acap.2009.02 .008

Wright, M. O., Masten, A. S., \& Narayan, A. J. (2013). Resilience processes in development: Four waves of research on positive adaptation in the context of adversity. In S. Goldstein \& R. B. Brooks (Eds.), Handbook of resilience in children (pp. 15-37). New York, NY: Springer. doi: 10.1007/978-1-4614-3661-4_2

Received July 9, 2013

Revision received February 28, 2014 